\title{
Monitoring the gray whale sound exposure mitigation zone and estimating acoustic transmission during a 4-D seismic survey, Sakhalin Island, Russia
}

\author{
Roberto Racca $^{1, *}$, Melanie Austin ${ }^{2}$, Alexander Rutenko ${ }^{3}$, Koen Bröker ${ }^{4}$ \\ ${ }^{1}$ JASCO Applied Sciences (Canada) Ltd., 2305-4464 Markham Street, Victoria V8Z 7X8, BC, Canada \\ ${ }^{2}$ JASCO Applied Sciences (Alaska) Inc., 200-310 K Street, Anchorage, AK 99501, USA \\ ${ }^{3}$ V.I. Il'ichev Pacific Oceanological Institute FEB RAS, ul. Baltiiskaya 43, Vladivostok 690041, Russia \\ ${ }^{4}$ Shell Global Solutions, Lange Kleiweg 40, 2288GK Rijswijk, The Netherlands
}

\begin{abstract}
A seismic survey conducted in the proximity of the nearshore feeding grounds of gray whales Eschrichtius robustus off northeastern Sakhalin Island, Russia, required the development of a comprehensive monitoring and mitigation plan. Prior to the execution of the seismic survey, the sound levels from the airgun array source were modelled for all seismic acquisition lines. This yielded estimated shoreward boundaries for an assumed disturbance threshold of $156 \mathrm{~dB}$ re $1 \mathrm{\mu Pa}^{2}$-s sound exposure level (SEL) that allowed an assessment of which lines would require more stringent mitigation. To enable prediction of the sound front under variable propagation conditions, a set of acoustic footprints with a realistic range of parameters was pre-computed. In the field, an acoustic monitoring network of 9 bottom-deployed stations with tethered radio buoys transmitted full waveform data to a shore-based monitoring post. The signals were processed to yield pulse levels for comparison to the model predictions. The appropriate footprint was selected on the basis of the pulse levels received during the initial minute of a seismic line and communicated to observation teams. To further ensure the sustained accuracy of the selected footprint during a line acquisition, the modelled levels were compared in real time to the measured readings as the source moved past the line of monitoring stations; they were consistently found to match the incoming received sound levels within an accepted tolerance of $3 \mathrm{~dB}$. This selection approach resulted in the best available estimation of acoustic exposure even through significant temporal changes in the hydrological conditions.
\end{abstract}

KEY WORDS: Western gray whale $\cdot$ Eschrichtius robustus $\cdot$ Acoustics $\cdot$ Sound exposure $\cdot$ Seismic survey $\cdot$ Disturbance

\section{INTRODUCTION}

Airgun arrays are the primary technology employed for offshore hydrocarbon exploration. These arrays emit impulsive pressure signals, the reflected signals of which are used to image sub-bottom seafloor layers. The resultant acoustic pressure waves propagate through the surrounding water with the potential to cause harm to marine life at ranges close to the airgun array and to elicit behavioural responses over larger areas (Nowacek et al. 2007). The

${ }^{*}$ Corresponding author: roberto.racca@jasco.com airgun impulses are mainly composed of frequencies below $200 \mathrm{~Hz}$, a frequency range that overlaps with the optimal hearing sensitivity in mysticetes (Southall et al. 2007).

A population of gray whales is known to feed during summer in the waters where Sakhalin Energy Investment Company (SEIC) carried out its 2010 4-D Astokh seismic survey, NE Sakhalin Island, Russia. Gray whales have been previously observed to respond to the pulsed sounds associated with seismic surveys (Malme et al. 1986, 1988, Gailey et al. 2007a, 
Johnson et al. 2007, Yazvenko et al. 2007). It was recognized that airgun sounds from the 2010 survey would have the potential to cause disturbance to the gray whale feeding activities. As such, a detailed acoustic monitoring study formed part of the monitoring and mitigation plan designed by SEIC and the IUCN's Western Gray Whale Advisory Panel (WGWAP) through its Seismic Survey Task Force to minimize survey impacts (IUCN 2008b, 2009, 2010, Bröker et al. 2015). The acoustic monitoring infrastructure included a line of telemetric real-time bottom-anchored buoys transmitting full waveform data to shore, an evolution of a conceptually similar design used to monitor a seismic survey in an adjacent region in 2001 (Rutenko et al. 2007).

The acoustic monitoring study consisted of 3 components: predictive numerical acoustic modelling; in-field source sound level verification measurements; and real-time sound level monitoring to support the survey mitigation protocol. The numerical model results were used to estimate a priori the spatial extent of propagation of airgun sounds. In addition, a suite of model outputs was generated for a range of propagation conditions that the authors believed could realistically be expected to occur throughout the survey. From this collection, an appropriate model was selected in real time to best reflect the propagation conditions for each line of acquisition. Real-time telemetered acoustic data from 9 acoustic monitoring buoys enabled the live selection of the model parameterization that best matched the observed sound levels. The propagation model output, in turn, provided an estimate of the spatial boundary for sound levels with the potential to elicit behavioural disturbance, demarcating the regions requiring focussed observations and within which additional shut-down protocols would apply. This closed-loop mitigation approach provided the greatest possible confidence in the estimation of the behavioural threshold boundary for each line of the survey, even in case of rapidly changing (spatially or temporally) propagation conditions.

This paper provides a description of each component of the acoustic monitoring study. The deployment arrangement and the technical details of the acoustic recording equipment are described, as are the methods used for the modelling, validation, data collection and data analysis. The outcome of the acoustic program is summarized including discussions of the model-data comparisons and the efficacy of the real-time monitoring. In addition, consideration is given to the further use of sound level estimation techniques post-survey to generate spatially distributed acoustic covariates for statistical analyses aimed at detecting any significant correlation between sound exposure and changes in whale distribution or behaviour.

\section{MATERIALS AND METHODS}

\section{Operational design}

The real-time aspect of the acoustic monitoring study was facilitated by a network of radio-transmitting, autonomous underwater sound measurement nodes. Nine digital, radio-transmission capable, autonomous underwater acoustic recorders (AUAR, Pacific Oceanological Institute) were distributed along the approximate boundary of the gray whale feeding area (Fig. 1). This boundary, referred to as the perimeter monitoring line (PML), was based on gray whale distribution data for the region of the seismic survey (IUCN 2009, Muir et al. in press c). The PML was

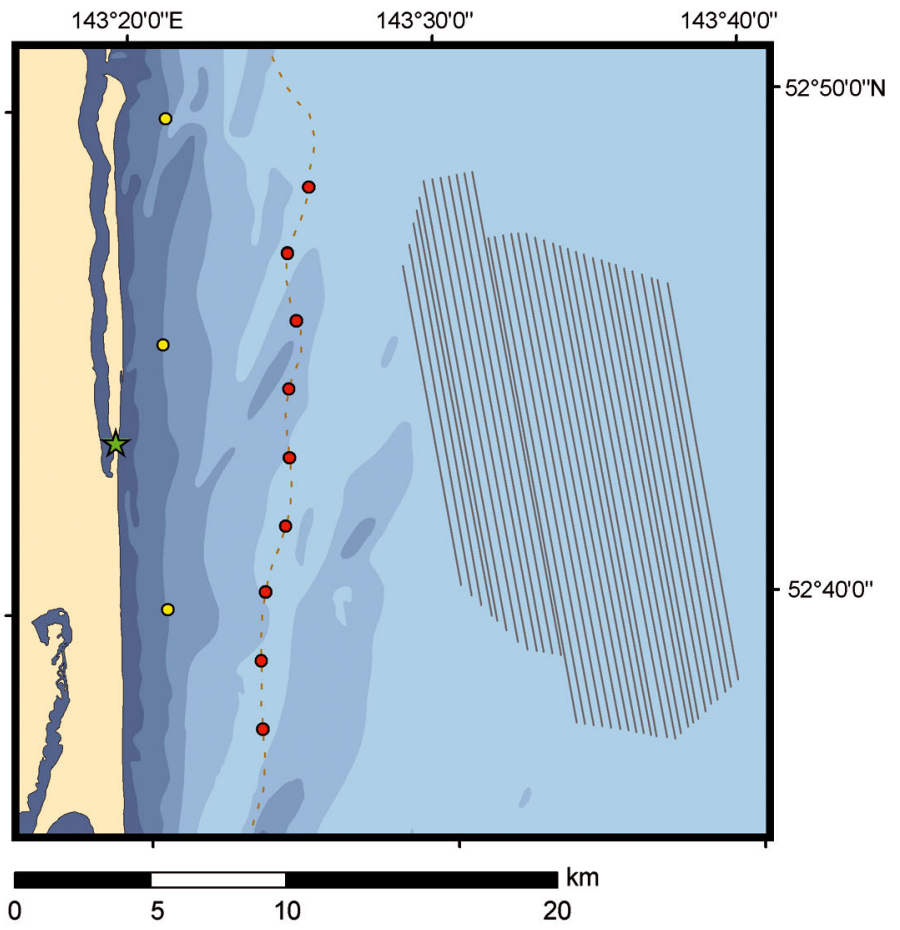

Fig. 1. Study area showing survey track lines (straight grey lines), the acoustic perimeter monitoring line (PML) defined by the 9 autonomous underwater acoustic recorder (AUAR) stations (red dots), AUARs along the $10 \mathrm{~m}$ bathymetry contour (yellow dots), and the shore-based acoustic monitoring station (green star)

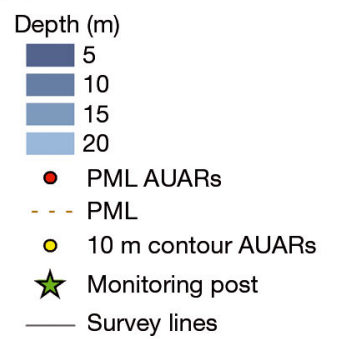


roughly $20 \mathrm{~km}$ in length, oriented generally northsouth, parallel to the coast and approximately along the $20 \mathrm{~m}$ isobath. Three non-transmitting autonomous recorders were also deployed inshore of the PML, approximately along the $10 \mathrm{~m}$ isobath, to provide archival sampling of sound levels in shallower water that could be used in post-survey analyses.

A shore-based receiving station that housed telemetry-reception and data-processing equipment was constructed on the coast half-way along the PML. Nine dipole antennas on masts near the station, individually pointed in the direction of the 9 PML telemetric buoys, picked up the digital signals broadcast by the AUARs. From this receiving post an acoustic monitoring team tracked the sound levels received at the 9 PML nodes throughout the survey. The acoustic monitoring team communicated with teams of behavioural observers posted onshore at the northern and southern boundaries of the PML, as well as on a vessel within the survey grid. The observation teams employed a GIS utility that combined modelled sound exposure contours with visually localized animal positions to enable sound exposure threshold assessments (Bröker et al. 2015). The observers loaded the appropriate (as determined by the acoustic team) sound exposure contour into the GIS utility and, based on that boundary, determined whether any observed whales might be exposed to sound above a threshold level. Exposure assessments were thus current with local sound propagation conditions.

\section{Monitoring equipment}

A challenging aspect of the acoustic monitoring program was the requirement to provide to a shorebased team of analysts real-time measurements of the acoustic pulse levels from the airgun array source as received at 9 stations along the PML. This required establishing a reliable radio telemetry link from each station to a single receiving installation on land; the ranges could be as much as $12 \mathrm{~km}$. While directional antennas mounted on vertical masts and oriented toward individual offshore stations provided an enhanced radio signal gain at the receiving end, the transmitting buoys could only be equipped with an omnidirectional antenna elevated by a few 10 s of $\mathrm{cm}$ above the water surface. This demanded a radio telemetry technology impervious to the variations in signal strength and occasional drop-offs that would occur when a buoy was washed over by waves or tilted by sea motion to the point that the antenna would barely clear the surface. A number of potential solutions were tested under controlled conditions, exploring both the radio frequency range of the carrier signal and the digital encoding technique for the acoustic data. The option of analyzing the acoustic signal within the stations and only transmitting the level of detected pulses would (1) have pushed the limit of the processing capacity of the on-board data acquisition computers and (2) curtailed the ability of the scientists monitoring the telemetered data to perform any kind of diagnostic assessment based on the actual sound waveform. The design engineers at the Pacific Oceanological Institute (POI) chose therefore to encode and transmit the digitized signal at the highest possible sample rate compatible with the bandwidth of the radio data channel. The architecture of the digital telemetry system for the 2010 monitoring (Kovzel \& Rutenko 2009) was an evolution of previous designs featuring an analogue radio telemetry link (Borisov et al. 2008). The digital encoding allowed transmission of acoustic signals in a 2 to $2000 \mathrm{~Hz}$ band at a sample rate of $4168 \mathrm{~Hz}$ with a signal to noise ratio of $\geq 96 \mathrm{~dB}$, over ranges exceeding $25 \mathrm{~km}$ in optimal conditions. In parallel to the digital telemetry, acoustic data were also recorded to a hard disk drive in each station at a sample rate of $30 \mathrm{kHz}$ - the same sample rate used for digital recordings on the 3 non-transmitting AUARs along the $10 \mathrm{~m}$ bathymetry contour. A more detailed technical description of the telemetric equipment is provided in Supplement 1 (www.int-res.com/articles/suppl/ n029p131_supp.pdf).

\section{Sound metrics}

Several sound level metrics are commonly used to evaluate the loudness of impulsive noise and its effects on marine life. The zero-to-peak sound pressure level (SPL), or peak SPL ( $\mathrm{dB}$ re $1 \mu \mathrm{Pa})$, is the maximum instantaneous sound pressure level in a stated frequency band attained by an acoustic pressure signal, $p(t)$ :

$$
\text { Peak SPL }=10 \log _{10}\left[\frac{\max \left(\left|p^{2}(t)\right|\right)}{p_{0}^{2}}\right]
$$

where $p_{0}$ is $1 \mu \mathrm{Pa}$ and time $t$ spans the duration of 1 or multiple pulses. The peak SPL metric is commonly quoted for impulsive sounds. At high intensities, it can be a valid criterion for assessing whether a sound is potentially injurious; however, because the peak SPL does not account for the duration or bandwidth of a noise event, it is a poor indicator of perceived loudness. 
The root-mean square (rms) SPL ( $\mathrm{dB}$ re $1 \mu \mathrm{Pa})$ is the rms pressure level in a stated frequency band over a time window $(T, \mathrm{~s})$ containing the acoustic event:

$$
\operatorname{rms~SPL}=10 \log _{10}\left(\frac{1}{T} \int_{T} p^{2}(t) \mathrm{d} t / p_{0}^{2}\right)
$$

The rms SPL is a measure of the average pressure or of the effective pressure over the duration of an acoustic event, such as the emission of one acoustic pulse or sweep. Because the window length, $T$, is the divisor, events more spread out in time have a lower rms SPL for the same total acoustic energy density.

In studies of impulsive noise, $T$ is often defined as the ' $90 \%$ energy pulse duration' $\left(T_{90}\right)$ : the interval over which the pulse energy curve rises from 5 to $95 \%$ of the total energy. The SPL computed over this $T_{90}$ interval is commonly called the $90 \%$ rms SPL (dB re $1 \mu \mathrm{Pa})$ :

$$
90 \% \text { rms SPL }=10 \log _{10}\left(\frac{1}{T_{90}} \int_{T_{90}} p^{2}(t) \mathrm{d} t / p_{0}^{2}\right)
$$

The sound exposure level (SEL, dB re $1 \mu \mathrm{Pa}^{2}-\mathrm{s}$ ) is a measure of the total acoustic energy contained in one or more acoustic events. The SEL for a single event is computed from the time-integral of the squared pressure over the full event duration $\left(T_{100}\right)$ :

$$
\mathrm{SEL}=10 \log _{10}\left(\int_{T_{100}} p^{2}(t) \mathrm{d} t / T_{0} p_{0}^{2}\right)
$$

where $T_{0}$ is a reference time interval of $1 \mathrm{~s}$. The SEL is related to the total acoustic energy flux at some location during an acoustic event; it measures the total sound energy to which an organism at that location would be exposed.

The rms SPL and SEL are both computed from the integral of square pressure and thus are related by a simple expression, which depends only on the duration of the pulse energy time window $T$ :

$$
\begin{gathered}
\text { rms SPL }=\text { SEL }-10 \log _{10}(T) \\
\text { rms SPL }=\text { SEL }-10 \log _{10}\left(T_{90}\right)-0.458
\end{gathered}
$$

where the $0.458 \mathrm{~dB}$ factor accounts for the $T_{90}$ time window containing $90 \%$ of the total energy from the per-pulse SEL.

The rms SPL (which has commonly been used for defining acoustic exposure criteria) is extremely sensitive to the definition of the pulse length, which can be confounded by multipath and sub bottom arrivals and background noise. Small differences of modelled and measured pulse lengths can produce very different rms SPL values. Therefore, the acoustic monitoring program was designed around a behavioural threshold expressed as a SEL that provided a stable metric for comparison of measured and modelled levels. The relationship between rms SPL and SEL was used to derive an SEL-based behavioural threshold for the monitoring and mitigation program equivalent to an agreed $90 \%$ rms SPL threshold of $163 \mathrm{~dB}$ re $1 \mu \mathrm{Pa}$ (IUCN 2008b). To this end, high frequency resolution full-waveform modelling of airgun array pulses was performed for several propagation radials extending shoreward from shot points along the most inshore survey line. The analysis showed that for the broadside radials difference between the rms SPL and SEL metrics was an essentially constant $7 \mathrm{~dB}$ at the propagation range to $163 \mathrm{~dB}$ re $1 \mu \mathrm{Pa}$ rms SPL, and was bounded by that value for more slanted radials. This enabled the use of the third-octave modelled contour for $156 \mathrm{~dB}$ re $1 \mathrm{\mu Pa}^{2}$-s per-pulse SEL as a cautionary surrogate, at least in the shoreward direction, for its $163 \mathrm{~dB}$ re $1 \mu \mathrm{Pa}$ rms SPL counterpart (IUCN 2008b).

Due to dispersion, the impulsiveness of airgun pulses decreases with propagation range. Impulsiveness can be quantified using kurtosis $(\beta)$, defined as the ratio of the fourth moment to the squared second moment of the instantaneous sound pressure:

$$
\beta=\frac{\frac{1}{N} \sum_{N}\left(p_{i}-\bar{p}\right)^{4}}{\left[\frac{1}{N} \sum_{N}\left(p_{i}-\bar{p}\right)^{2}\right]^{2}}
$$

where $p_{i}$ is the $i$ th sample of instantaneous sound pressure, $\bar{p}$ is the arithmetic mean of sound pressure, and $N$ is the total number of data samples. This calculation requires the sampling window to contain at least one complete waveform of the sound of interest. Erdreich (1986) proposed that sounds more sharply peaked than a normal distribution $(\beta>3)$ are impulsive whereas less sharply peaked sounds $(\beta \leq 3)$ are not.

The SNR is the ratio of signal power $\left(P_{\mathrm{s}}\right)$ to noise power corrupting the signal $\left(P_{\mathrm{n}}\right)$. It compares the level of the desired signal to the level of the background noise. The greater this ratio, the less obtrusive the background noise. SNR is defined in decibels as:

$$
\mathrm{SNR}=10 \log _{10}\left(\frac{P_{\mathrm{s}}}{P_{\mathrm{n}}}\right)
$$

\section{Modelling approach}

The monitoring and mitigation plan for the Astokh survey relied on pre-calculated noise footprint estimates from mathematical computer models. A para- 
bolic equation (PE) numerical sound propagation model (MONM, JASCO Applied Sciences, described in Austin \& Chapman 2011) was coupled with an airgun array source model (AASM, JASCO Applied Sciences, MacGillivray 2006) to compute underwater sound levels as a function of range, depth and direction from the airgun array. MONM is based on the widely accepted code RAM (Collins 1993), modified to account for shear wave losses at the sea floor by applying a complex multiplicative factor to the seabed density (Zhang \& Tindle 1995). This approach is more than 5 times faster than code that treats shear wave propagation in a robust sense, yet it produces results that are nearly identical to the reference approach for uniform low shear speed shallow water environments with silt and sand bottoms (Hannay \& Racca 2005). The PE code does not model potential interface waves near the seafloor at frequencies of a few $\mathrm{Hz}$, but likely these would be outside the sensitive frequency range of gray whales.

The PE propagation code provided frequencydependent sound transmission loss (TL) along radial transects between a source position and a 3-dimensional grid of receiver positions. When combined with directional, frequency-resolved source levels from AASM, the result was a grid of underwaterreceived sound levels used to estimate sound exposure within the gray whale feeding area. Sound propagation was modelled at the center frequency of each 1/3-octave band between 5 and $2000 \mathrm{~Hz}$. The received sound levels were then summed over frequency to provide broadband $(5-2000 \mathrm{~Hz})$ exposure estimates.

Accurate model estimates were dependent on an appropriate selection of MONM input variables that parameterize the sound-influencing characteristics of the environment. These parameters included the water column sound speed (a depth-dependent function of temperature and salinity) and geo-acoustic properties of the seafloor (sound speed and attenuation for both shear and compressional waves, and density). An average of hydrological samplings of the water column collected over several years provided a base condition for the early summer period, when the survey would be conducted, which exhibited a downward refracting water column sound speed profile. In the absence of specific measurements of geoacoustic properties, a base set of values for sediment density and compressional and shear wave attenuation was obtained from published information for generic sediment types (Hamilton 1976, 1980). Sediment density $\left(1772 \mathrm{~kg} \mathrm{~m}^{-3}\right)$ and compressional wave attenuation $\left(0.14 \mathrm{~dB} \lambda^{-1}\right)$ were based on values for sandy silt on the continental terrace for terrigenous sediments. Shear wave attenuation $\left(13.6 \mathrm{~dB} \lambda^{-1}\right)$ was based on the average of values for diluvial sand and clay (19.8 $\left.\mathrm{dB} \lambda^{-1}\right)$ and for diluvial sand $\left(7.4 \mathrm{~dB} \lambda^{-1}\right)$. The approach for selecting compressional and shear wave speeds considered a finite set of possible combinations of these parameters to maximize agreement of predicted TL with measurements from dedicated sound propagation studies conducted over a number of source-receiver paths in the region (Borisov et al. 2005, Karnauhov et al. 2005). The possible values included 2 compressional speeds: 1750 and $2000 \mathrm{~m} \mathrm{~s}^{-1}$, and 3 shear speeds: 100, 200 and $300 \mathrm{~m} \mathrm{~s}^{-1}$. The fit against data (Hannay \& Racca 2005) was done by choosing the set of parameters that minimized the mean difference between model and data in 1/3-octave bands in the 50 to $500 \mathrm{~Hz}$ frequency range. The alternative of minimizing mean square difference was also considered, but occasional data outliers caused those fits to be less representative of the more self-consistent data points. The resulting parameters, slightly adjusted through later matching of model results with sound level measurements for offshore industrial activities in the same region, defined the Base model case for a representative set of propagation conditions (Table 1).

To quantify the variability of the model output for the Astokh 4-D survey due to uncertainty of the selected seafloor properties and anticipated temporal variation of the water column sound speed profile, the relative importance of each model input parameter was assessed through a sensitivity study (IUCN 2008a, JASCO in LGL 2010) using acoustic source properties and propagation radials consistent with the planned seismic survey operation. Shear wave propagation parameters were held fixed to nominal expected values for the investigation. The sound speed of compressional waves in the seafloor and the gradient of the sound speed in the water column were determined to have the strongest influence on the model output. Based on the results of the sensitivity study, 2 additional model cases (referred to as 'High' and 'Low') were constructed to represent the foreseeable limits of the sound propagation environment, within reasonable physical bounds. Model inputs were selected to parameterize conditions that would yield higher and lower sound propagation than the Base model case. The 'High' model case incorporated an isovelocity sound speed profile. This condition was reasonably expected to occur during the initial part of the survey shortly following ice break-up and would have resulted in enhanced propagation of sound compared to the 
Table 1. Acoustic model parameters for the Base, High and Low propagation cases. (a) Acoustic properties of the seafloor; (b) sound velocity profile in the water column. mbsf: metres below sea floor; P-wave: compressional wave; S-wave: shear wave

\begin{tabular}{|c|c|c|c|c|c|c|c|}
\hline \multirow{2}{*}{$\begin{array}{l}\text { (a) Depth } \\
\text { (mbsf) }\end{array}$} & \multicolumn{3}{|c|}{ P-wave speed $\left(\mathrm{m} \mathrm{s}^{-1}\right)$} & \multirow{2}{*}{$\begin{array}{l}\text { P-wave attenuation } \\
\qquad\left(\mathrm{dB} \lambda^{-1}\right)\end{array}$} & \multirow{2}{*}{$\begin{array}{l}\text { S-wave speed } \\
\left(\mathrm{m} \mathrm{s}^{-1}\right)\end{array}$} & \multirow{2}{*}{$\begin{array}{l}\text { S-wave attenuation } \\
\qquad\left(\mathrm{dB} \lambda^{-1}\right)\end{array}$} & \multirow{2}{*}{$\begin{array}{c}\text { Density } \\
\left(\mathrm{kg} \mathrm{m}^{-3}\right)\end{array}$} \\
\hline & Base & High & Low & & & & \\
\hline 0 & 1652 & 1692 & 1612 & 0.14 & 150 & 13.6 & 1772 \\
\hline 500 & 2152 & 2192 & 2112 & 0.14 & 150 & 13.6 & 1772 \\
\hline$>500$ & 2152 & 2192 & 2112 & 0.14 & 150 & 13.6 & 1772 \\
\hline \multirow[t]{2}{*}{ (b) Depth (m) } & \multicolumn{3}{|c|}{ Sound speed in water $\left(\mathrm{m} \mathrm{s}^{-1}\right)$} & & & & \\
\hline & Base & High & Low & & & & \\
\hline 0.0 & 1469 & 1470 & 1469 & & & & \\
\hline 0.9 & 1469 & 1470 & 1469 & & & & \\
\hline 2.5 & 1467 & 1470 & 1467 & & & & \\
\hline 3.1 & 1466 & 1470 & 1466 & & & & \\
\hline 5.1 & 1461 & 1470 & 1461 & & & & \\
\hline 6.8 & 1456 & 1470 & 1456 & & & & \\
\hline 8.0 & 1452 & 1470 & 1452 & & & & \\
\hline 9.0 & 1448 & 1470 & 1448 & & & & \\
\hline 10.2 & 1446 & 1470 & 1446 & & & & \\
\hline 11.5 & 1444 & 1470 & 1444 & & & & \\
\hline $30.0+$ & 1444 & 1470 & 1444 & & & & \\
\hline
\end{tabular}

Base case conditions. This isovelocity parameterization was combined with a slightly increased sound speed for compressional waves in the seafloor. At the other end, the 'Low' parameterization incorporated a slightly lower compressional wave sound speed compared to the Base case, which yielded a reduced sound propagation. These 3 parameterizations (Base, High, and Low) formed the foundation of a library of model outputs that were pre-computed for use during the survey. Table 1 lists the model parameters for the 3 model cases.

Two types of model outputs were generated for each model case. The first were area contours of perpulse SEL, maximized over depth to yield the most precautionary estimate, for several 10 s of source points along each seismic survey line. The second were sequences, indexed by source position for each pulse along a survey line, of per-pulse SEL at the sea floor estimated at the sites of 9 bottom-deployed acoustic telemetry stations.

The sound level contours were used to extract the maximum range in the shoreward direction from all source points along each seismic line to the prescribed behavioural threshold of $156 \mathrm{~dB}$ re $1 \mu^{2} \mathrm{~Pa}^{2}-\mathrm{s}$ per-pulse SEL. The envelope of these distances defined the static outline of the protection zone for each seismic line. Only the shoreward envelope was important because the most-utilized gray whale feeding grounds lay inshore from the survey area. A library was compiled of the protection zone boundaries for each of the 3 propagation conditions, each further modified by fixed $\mathrm{dB}$ offsets between -5 and $5 \mathrm{~dB}$ to yield a broader set of options; these precomputed 'model cases' were identified by the parameterization type and the offset (e.g. Base $+1 \mathrm{~dB}$, Low $-2 \mathrm{~dB}$ etc). Fig. 2 is a sample map comparing protection zone boundaries for different model cases.

The per-pulse received level sequences for the 9 receiving stations were used in real-time during the survey to select the model case that best matched the received data at the start of each line and to verify the model accuracy throughout the acquisition of each line. At the start of each seismic line, the modelled pulse sequences were compared to the true sound levels received at the 3 recording stations that were closest to the start of the line during the first minute of acquisition ( 6 or 7 airgun pulses). These true levels were input into a spreadsheet utility that calculated the average received levels from each station and determined which model case yielded a pulse sequence with the least residual between the modelled and measured values for the respective source positions. The utility also output a fixed $\mathrm{dB}$ offset if required to improve the match for a given model case. The optimal model case and offset that were deemed to best match the measured levels were relayed to the observation teams via an established radio communications protocol. The observation teams then loaded into their localization software the appropriate exposure boundary contour from the GIS library of modelled footprints. 


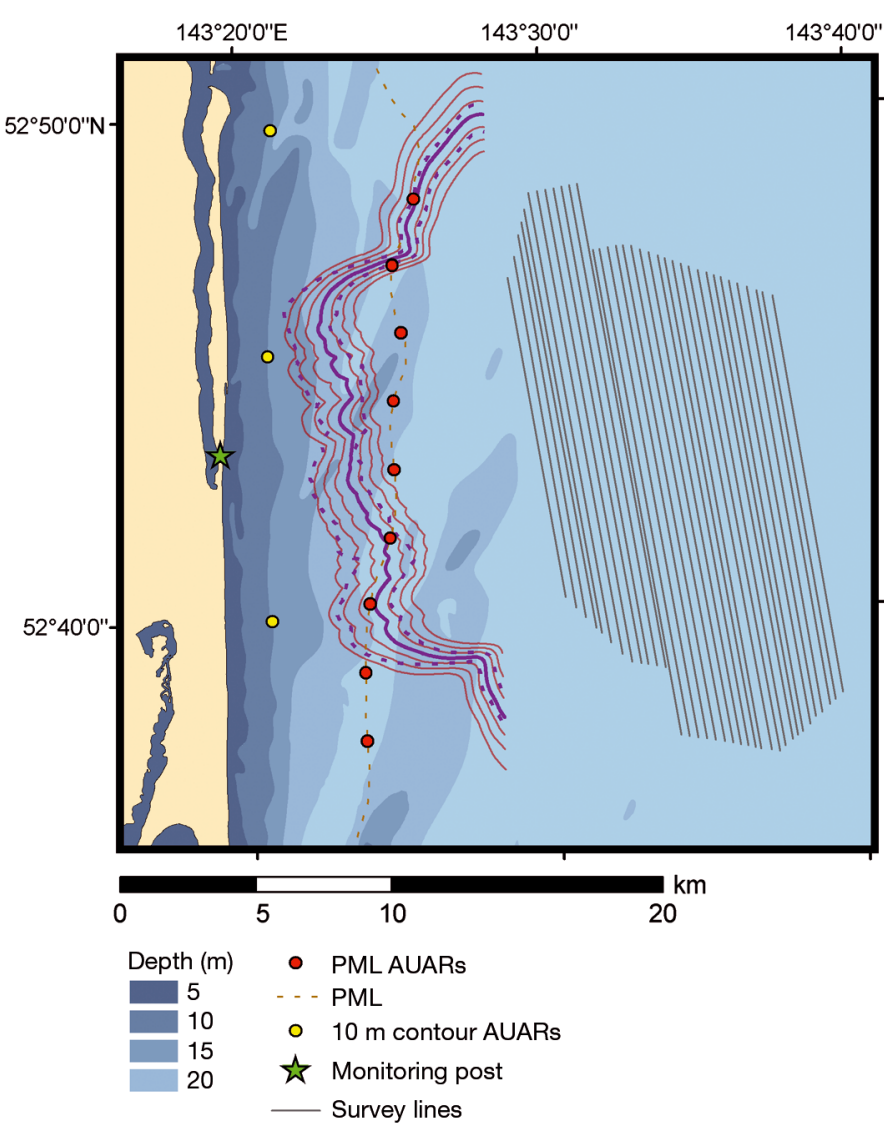

Fig. 2. Astokh 4-D seismic survey track lines (straight gray lines) and examples of the modelled behavioural protection zone boundaries for the most near-shore survey line under Base, Low, and High propagation regimes (solid and dashed purple lines) interleaved with finer level adjustments in $1 \mathrm{~dB}$ sound exposure level (SEL) steps (thin red lines). Also shown are the acoustic perimeter monitoring line (PML) defined by the 9 autonomous underwater acoustic recorder (AUAR) stations (red dots), AUARs along the $10 \mathrm{~m}$ bathymetry contour (yellow dots) and the shore-based acoustic monitoring station (green star)
During each survey line, the received pulse levels from each telemetry station were plotted in real time using a custom software application. The application also plotted a trace of the corresponding pulse sequence for the active model case allowing a direct comparison at a given sensor in real time. The mitigation plan stipulated that the measured pulse levels must remain within a tolerance band of $+3 \mathrm{~dB}$ from the modelled trace. If not, the boundary contour had to be updated with a more appropriate case from the library.

Fig. 3 is an example of the type of display used in the field to track the agreement between measured and modelled pulse levels. The software allowed a progressive selection of which receiving station to display so that monitoring was focused on the station nearest to the array broadside axis at any time throughout the line. Emphasis was placed on the broadside since that was where the array output was strongest (and also where the model most accurately matched measurements during a pre-season model validation as discussed below).

\section{Pre-season model validation approach}

In preparation for the critical use of the sound footprint modelling during the 2010 survey, a trial acquisition of seismic data in the same region was performed in 2009 to assess the validity of the model results with good quality measurements. The trial took place on 30 October 2009 (well past the peak period of the feeding season) as a seismic vessel transited through the Astokh area. The airgun array, which was about $20 \%$ larger in total volume than the
Fig. 3. Screen capture from the software used by the acoustics monitoring team showing the agreement between measured pulse levels (black trace) from the perimeter line sensor just ahead of the airgun array beam and the corresponding modelled levels (red line) during acquisition of seismic line L04. Measured levels from the 8 other sensors that were not actively important at the time of the screen capture are shown as green traces. The $+3 \mathrm{~dB}$ tolerance band is also indicated (blue dashed line). SEL: sound exposure level; AUAR: autonomous underwater acoustic recorder; KP: kilometer point (distance travelled by the vessel along the seismic line)

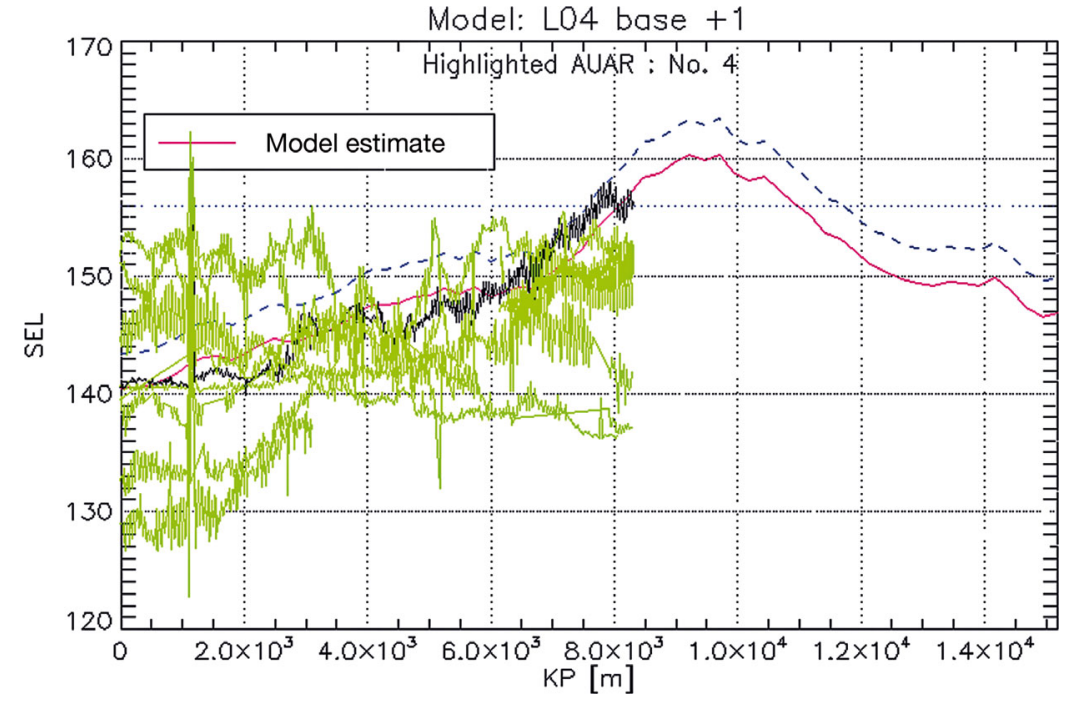


source to be used in 2010, was deployed for a short run on a direct north-south course $1.5 \mathrm{~km}$ inshore of the Piltun-Astokh A (PA-A, also known as Molikpaq) platform at its closest approach, starting about $5 \mathrm{~km}$ north of the platform and ending about $2 \mathrm{~km}$ south of it.

Three mini-AUARs (short-autonomy non-transmitting AUARs in a compact pressure case) were deployed at nominal ranges of 2.5, 3.5 and $5 \mathrm{~km}$ from PA-A along a westward radial. This provided measurements of the propagated levels from the seismic array at ranges of about 1,2 and $3.5 \mathrm{~km}$ from the closest point of approach (CPA). By reference to the layout of the 2010 operations, the test track spanned roughly the central one-third of the Astokh 4-D survey line at about one-third of the offshore width of the survey area, but the recorders were substantially closer to the track than the range from the survey
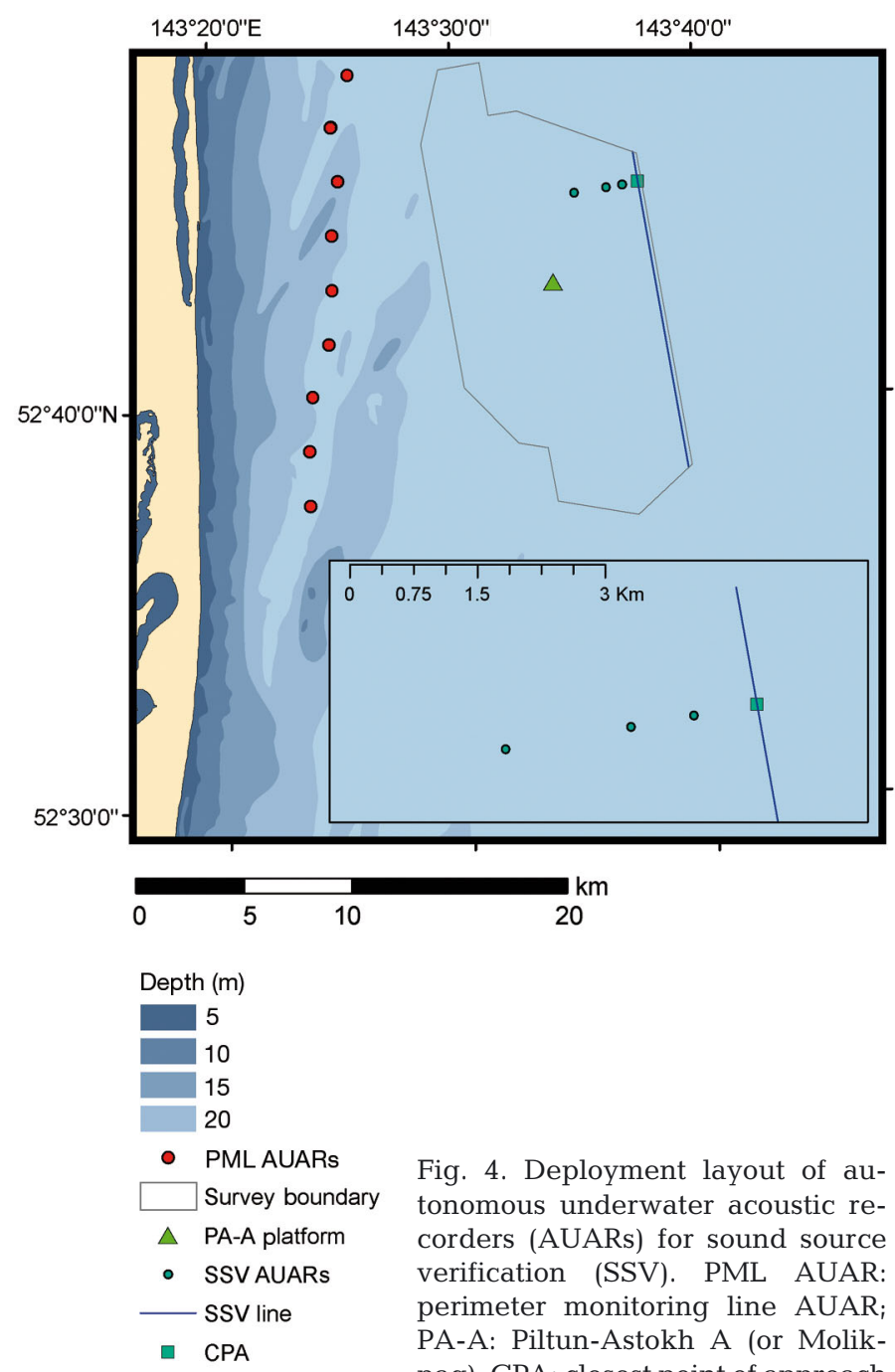

Fig. 4. Deployment layout of autonomous underwater acoustic recorders (AUARs) for sound source verification (SSV). PML AUAR: perimeter monitoring line AUAR; PA-A: Piltun-Astokh A (or Molikpaq); CPA: closest point of approach lines to the PML. All distances were known precisely from GPS-based documentation of the mini-AUAR drop points and the navigational logs of the seismic vessel which provided co-ordinates and times of each source pulse.

\section{Sound source verification (SSV) approach}

An important component of the mitigation plan was the establishing of an exclusion zone around the seismic vessel to ensure that no marine mammals are exposed to pulse levels that may cause physical damage $(90 \%$ rms SPL of $180 \mathrm{~dB}$ re $1 \mu \mathrm{Pa}$ for cetaceans and $190 \mathrm{~dB}$ re $1 \mu \mathrm{Pa}$ for pinnipeds). If marine mammals are seen within the applicable exclusion radius, then the survey must shut down until animals are no longer believed to be within it. This is common practice for many seismic surveys. Prior to the survey the radius was conservatively estimated as $2 \mathrm{~km}$ using modelled data. The objective of the SSV study was to measure underwater acoustic levels during the acquisition of a regular survey line and thus confirm or revise the estimated marine mammal exclusion zone radii. Full-waveform acoustic data were collected on 3 dedicated mini-AUAR recorders.

The deployment configuration of the SSV acoustic recorders (Fig. 4) was defined to capture sound levels as a function of distance broadside of the array (perpendicular to the path of the seismic vessel). On 17 June 2010, the seismic vessel sailed from north to south along the most eastern traverse of the survey pattern, performing a full geophysical data acquisition. The line began approximately $1.5 \mathrm{~km}$ from the point of closest approach to the row of SSV recorders and extended about $13.5 \mathrm{~km}$ past it.

\section{RESULTS AND DISCUSSION}

\section{Pre-season model validation}

The modelling of the point-source equivalent far field directional source levels from the airgun array and their propagation through the acoustic environment were performed using the AASM source model and the MONM propagation model as previously described. For this validation study, the same acoustic environment parameters were used as for the Base case of the Astokh 4-D modelling, with the exception of the water sound velocity profile that was matched to the later season in which the trial took place. Neither the modelled nor the measured sound levels for 
this operation, of course, would be directly comparable to those from the 2010 survey because of the different source specifications.

The model results were computed for every seismic shot position at each of the 3 receiver locations, at a depth just off the sea floor to match the position of the hydrophones. The values of both the measured per-pulse SEL metric and its modelled estimate are plotted against the along-line offset from CPA in the figures that follow. Fig. 5 shows the results for the receiver at $1 \mathrm{~km}$ off the sail line, Fig. 6 for the receiver at $2 \mathrm{~km}$ and Fig. 7 for the receiver at $3.5 \mathrm{~km}$.

The agreement between model and measurement was deemed reasonable considering that no special effort was made to tune the notional water sound velocity profile to improve the quality of the fit. The model tended to overestimate the received levels in the broadside direction (near CPA), providing a precautionary result. Along the approach run (left of the CPA in the plots), the model matched well the trend of the measured data at 1 and $2 \mathrm{~km}$ from the sail line, even though it failed to fully account for smallerscale oscillations that may depend on fine conformation of the seafloor topography not resolved in the modelling bathymetry database. The sudden drop in measured levels along the departing run was not fully rendered by the model, resulting in overestimation; again a local smaller-scale conformation of the sea floor (which caused an asymmetry in what should be an essentially mirror image pattern) was a probable cause of the deviation. The only discrepancies that raised concern from a precautionary standpoint were the higher measured levels relative to model estimates seen along the approach run for the 2 and $3.5 \mathrm{~km}$ receivers. The received levels rose steeply above the model predictions starting at an along-line offset approximately equal to the receiver distance from the line and remained

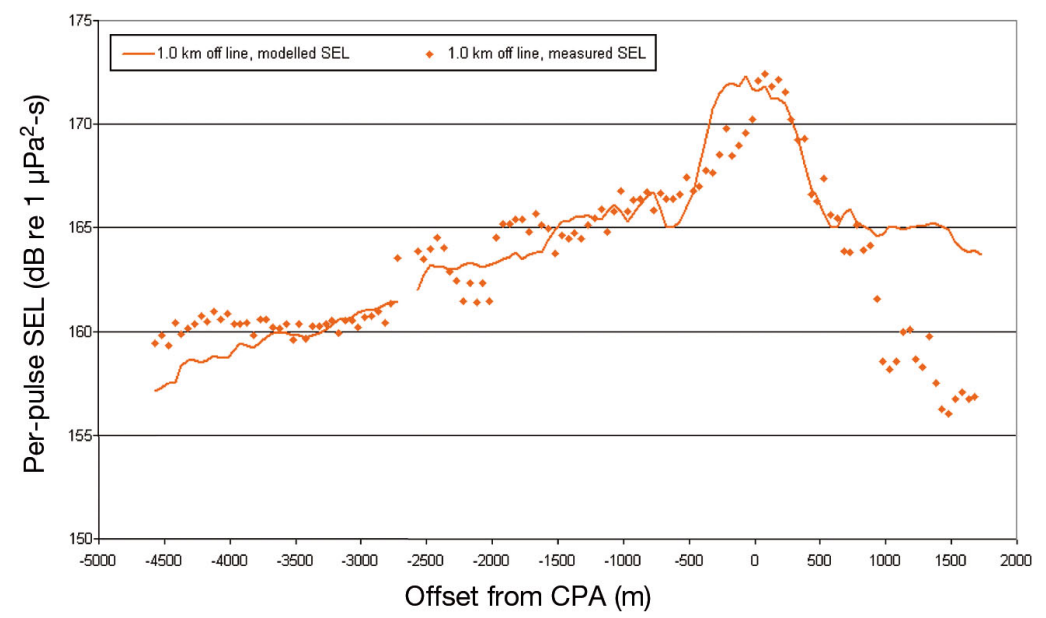

Fig. 5. Measured (individual dots) and modelled (continuous line) per-shot sound exposure level (SEL) metric for a receiver $1 \mathrm{~km}$ off the sail line, plotted against along-line offset from closest point of approach (CPA)

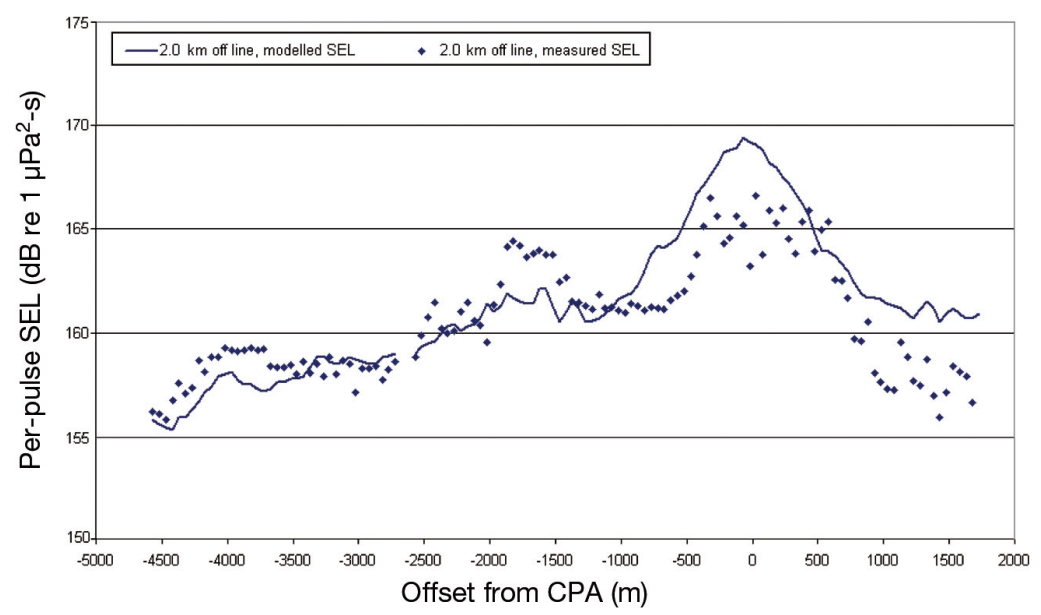

Fig. 6. Measured (individual dots) and modelled (continuous line) per-shot sound exposure level (SEL) metric for a receiver $2 \mathrm{~km}$ off the sail line, plotted against along-line offset from closest point of approach (CPA)

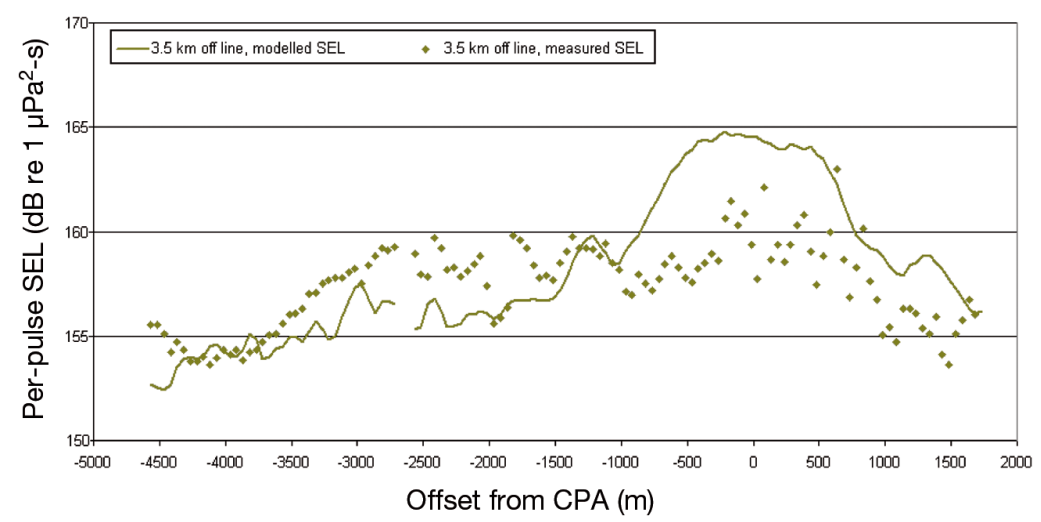

Fig. 7. Measured (individual dots) and modelled (continuous line) per-shot sound exposure level (SEL) metric for a receiver $3.5 \mathrm{~km}$ off the sail line, plotted against along-line offset from closest point of approach (CPA) 
high up to about $1.5 \mathrm{~km}$ before CPA, exceeding by as much as $+3 \mathrm{~dB}$ the model estimates which followed a gradual, more conventional rising trend. One possible explanation for these anomalies was that the airgun array source model might underestimate some of the directional lobes off the broadside axis, resulting in lower pulse level predictions than in reality. However, the fact that the discrepancy was asymmetric on the 2 sides of CPA, and did not manifest itself on the $1 \mathrm{~km}$ receiver, discounted this hypothesis in favour of the anomalies in sound propagation being caused by local features of the seafloor not accurately rendered in the bathymetry dataset (an effect that indeed would be observed prominently later in the course of the survey monitoring). In terms of the estimation of the shoreward sound levels fronts from the Astokh survey, however, the observed broadening of the off-axis sound footprint would not have had a significant influence even had it been systematic. For practical purposes, the key factor in the validation was that the broadside sound propagation threshold range and the mean trend of its decay with offset from CPA were closely matched quantitatively by the default parameterization of the model.

An additional objective of the trial was to validate on the collected data the agreement of pulse level metrics calculations between the processing codes (one for real-time monitoring and the other for analysis of the stored acoustic data after retrieval) that would be used by different groups during the 2010 seismic survey monitoring and post-analysis. This was key to achieving consistent results in different phases of the operation, from the sound source verification to the real-time processing of the telemetered data from the PML measurement stations, to the postseason analysis. In a comprehensive cross-check of the full data sets from all 3 stations, the processing codes were found to agree on the values of sound level metrics that included the per-pulse SEL and the $90 \%$ pulse energy rms SPL to good precision consistently within $0.1 \mathrm{~dB}$ and typically within one-tenth of that tolerance.

\section{Sound source verification}

For the purpose of the initial determination of the exclusion zone, only the shot levels recorded at the CPA were analyzed; a subsequent more thorough analysis used a broader set of points, made fewer simplifying assumptions and yielded results that confirmed the validity of the initial approach. Both calculations are discussed here.

The initial estimation of exclusion zone radii was performed through an analysis of rms sound levels measured at the CPA as a function of receiver distance from the line. This analysis involved fitting a least-squares linear function through the rms levels measured at the 3 acoustic recorders plotted against the logarithm of the receiver range. The inset table in Fig. 8 shows the data used in the calculation, with the regression graph and corresponding formula shown in the figure.

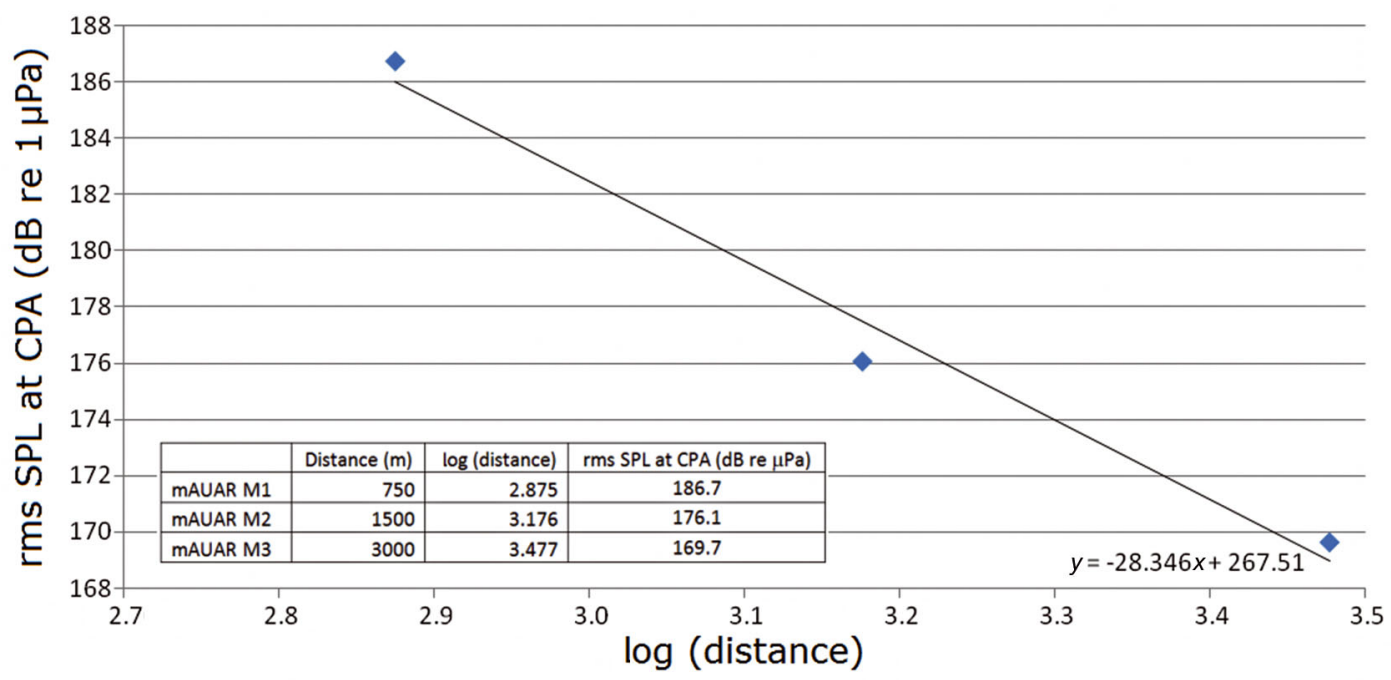

Fig. 8. Regression plot through root-mean square (rms) sound pressure levels (SPL) vs. logarithm of distance from the seismic line. CPA: closest point of approach. Inset table shows the original data used in the regression. mAUAR: mini autonomous underwater acoustic recorder 
The regression equation provided the following distances corresponding to rms SPL threshold values of 180 and $190 \mathrm{~dB}$ re $1 \mu \mathrm{Pa}$ :

$$
\mathrm{r}_{180 \mathrm{~dB}}=1220 \mathrm{~m} \quad \mathrm{r}_{190 \mathrm{~dB}}=540 \mathrm{~m}
$$

As agreed with the WGWAP (see Bröker et al. 2015), the calculated radius for $180 \mathrm{~dB}$ was increased by a cautionary safety margin of $20 \%$, yielding a cetacean exclusion zone distance of $1464 \mathrm{~m}$ or $1.5 \mathrm{~km}$ in practical terms. This value was therefore used to replace the $2 \mathrm{~km}$ safety radius in the original mitigation plan. Following the completion of the survey, a more accurate calculation that took into account the positional data of the source vessel was performed for corroboration, and its results confirmed the $1.5 \mathrm{~km}$ value. This revised SSV analysis is described in Supplement 2 (www.int-res.com/articles/suppl/ n029p131_supp.pdf).

\section{Measured pulse levels at the PML}

Acoustic data were successfully collected at the 9 PML nodes throughout the entire survey, providing a comprehensive suite of data that characterized the shoreward propagation of sound from the airgun array. The variation in received levels highlighted 2 particular propagation effects, one attributed to finer-scale features of the bathymetry and the other to the dynamic hydrography of the survey region.

The bathymetric effect exhibited itself through variability in the levels received at different PML nodes over similar propagation ranges. During realtime monitoring it was observed that the levels received when the array was broadside of node AUAR 6 (nodes are numbered sequentially from the north) were consistently lower by several $\mathrm{dB}$ than those received at the other sensors when broadside to the array. These differences were greater than could be expected given the low variability in the shoreward distance from the survey lines to the various nodes. The measured levels on AUAR 6 were consistently lower than model estimates indicated.

Post-season examination of the measured seafloor relief revealed a $1 \mathrm{~km}$ wide ridge approximately $1 \mathrm{~km}$ offshore AUAR 6, where the water depth decreased to $15 \mathrm{~m}$ (Fig. 9, Rutenko et al. 2012). This ridge (not present in the bathymetric dataset used as model input) shielded AUAR 6 from water-borne arrivals of the low-frequency components (below approximately $90 \mathrm{~Hz}$; Rutenko et al. 2012) of the airgun pulses. This resulted in reduced received sound levels at that node in comparison to the other 8 sen- sors. A weak but similar bathymetric effect was observed at AUAR 9 due to a less prominent ridge immediately in front of the receiver (Fig. 9).

The second effect related to a temporal shift of the sound propagation conditions over the cusp of a seasonal change of the hydrography. Around 21 June there was a shift of the line model best fit case selections from high sound propagation cases to those more closely resembling the Base model case. Postseason comparison of hydrological records collected on 18 June and on 2 July showed that the water column sound speed profile shifted from essentially an isovelocity profile to a downward refracting profile (Rutenko et al. 2012). The latter profile resulted in sound being more focussed toward the acoustically absorbing seafloor, which Rutenko et al. (2012) showed led to an increase of propagation loss for the airgun pulses of approximately $3 \mathrm{~dB}$. To investigate this change of the propagation conditions, the model case assignment for each line acquisition was plotted

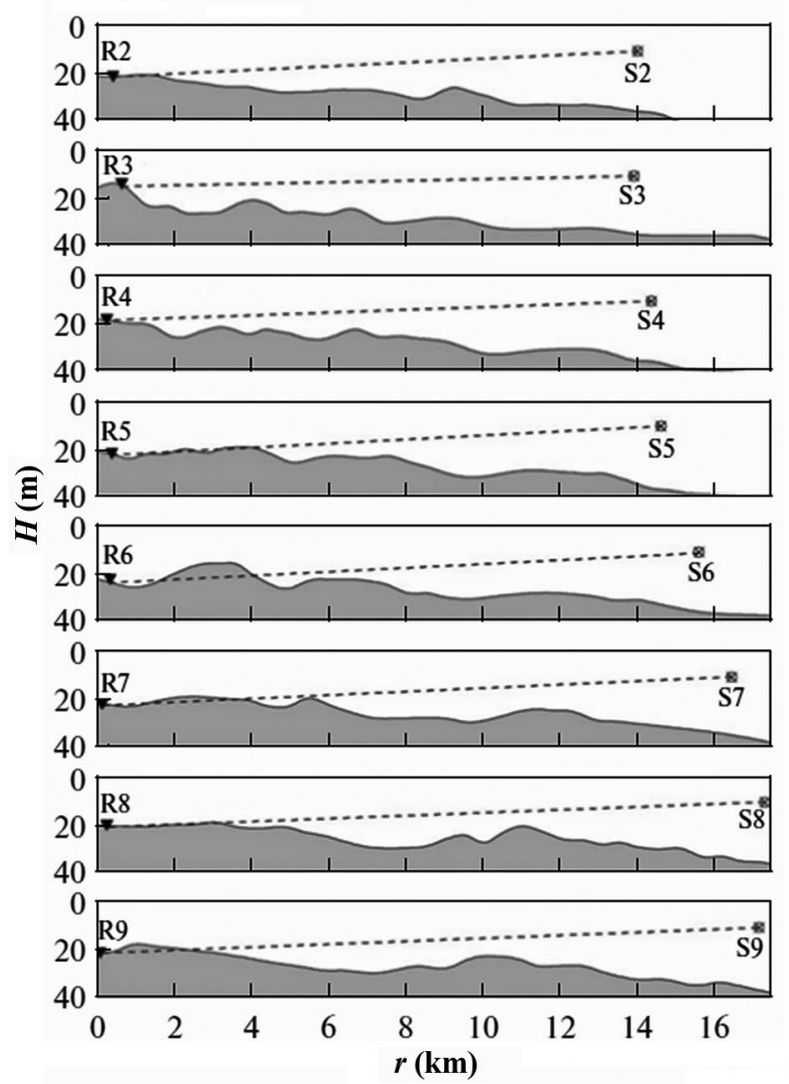

Fig. 9. Bottom profiles for 8 source-receiver propagation paths corresponding to seismic source positions approximately broadside autonomous underwater acoustic recorders (AUARs) along the perimeter monitoring line (PML) (from Rutenko et al. 2012). H: depth below water surface; $r$ : range from recorder position; R1-R9: AUAR locations; S1-S9: seismic source locations 


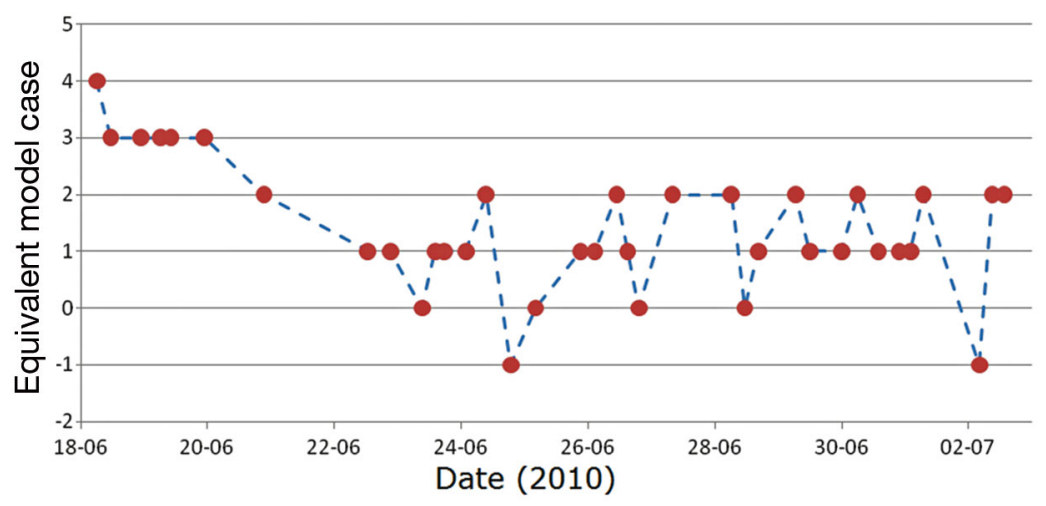

Fig. 10. Plot of Base-referenced equivalent offset versus line start chronology for all model cases selected during the survey. Red dots: model offset used on a certain date; dashed blue line evidences the offset trend over time; dates given as dd-mm

in chronological order and the 3 model cases (Low, Base and High) were converted to an equivalent offset referenced to the Base model case. This allowed all model case assignments to be compared across time, in a linear fashion, which was possible because the outputs from the 'Low $+1 \mathrm{~dB}^{\prime}$, 'High $-3 \mathrm{~dB}^{\prime}$, and Base model cases were found to be essentially equivalent. Fig. 10 is a plot of the Base-referenced equivalent model cases (expressed as a dB offset from the Base model case) for all survey lines by acquisition date. Between 20 and 22 June, the equivalent model case offsets transitioned from values greater than or equal to $3 \mathrm{~dB}$ to values that hovered around $1 \mathrm{~dB}$. Although the hydrological conditions may not be the only explanation for this transition and a more detailed analysis has not been performed, this is consistent with the measured shift of the propagation conditions during the period of the seismic survey reported in Rutenko et al. (2012) and Rutenko \& Sosnin (2014). After this transition occurred, the Base +1 model case was the case most often selected. The post-operation revisiting of the model case assignments in terms of a common Base-referenced offset also revealed that ultimately the choice between the 3 parametrizations was somewhat arbitrary, since minor relative variations in the received levels at the start of a line could make the difference between selecting a Low propagation case with positive offset and a High propagation case with negative offset. This observation suggested that the option of simplifying the per-line model tuning to a single prevailing parametrization and an adjustable $\mathrm{dB}$ offset should be considered in future applications of the approach.

\section{Analysis of difference between measured and modelled pulse levels}

To provide an overview of the comparison between measured and modelled SELs for a complete survey line, broadside portions of the measured received level traces were extracted and compiled into a piece-wise composite. This reduced the cluttered display of data from all receivers, as shown in Fig. 3, to only the relevant segments for individual sensors. These were stitched together to replicate the modelled trace derived from the envelope of the shoreward broadside maxima. The composite shows only the portion of trace for each PML sensor within $1.25 \mathrm{~km}$ on either side of the corresponding CPA of the airgun array for

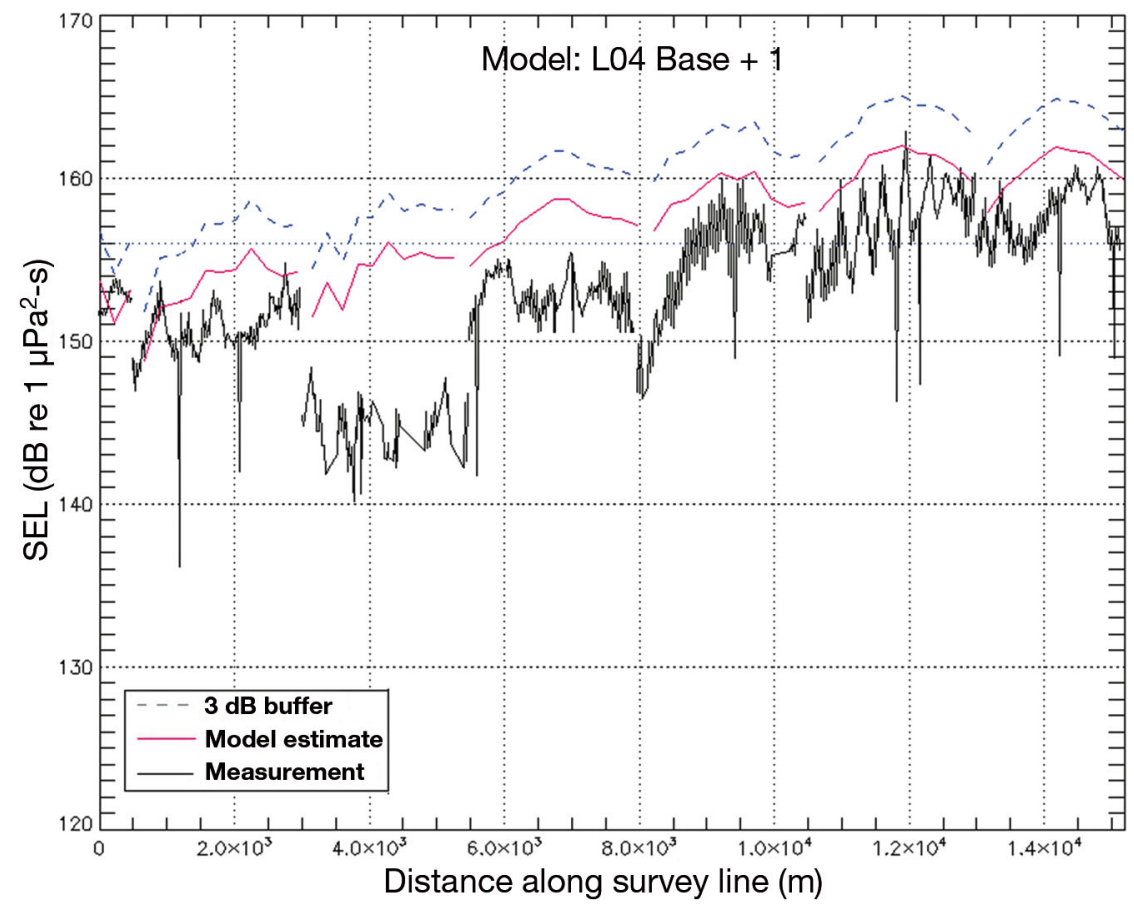

Fig. 11. Composite plot showing the agreement between measured (black) and modelled (red) pulse levels during acquisition of seismic line L04. The $+3 \mathrm{~dB}$ tolerance band is also indicated (dashed blue). SEL: sound exposure level 
that sensor. Fig. 11 is an example of such a plot for seismic line L04, showing that the model accurately estimated the broad scale trend of the received levels and the local maxima at each CPA. The anomalous decrease of received sound levels with the passing of the airgun array abeam AUAR 06, discussed earlier on, is also evident.

\section{Acoustic covariates calculation for multivariate analyses}

Acoustic propagation modelling allows not only forecasting of the sound exposure boundaries of the seismic survey prior to its execution but also, once the sequence and extent of the lines acquired was available at the end of the operation, estimation of the instantaneous (per-pulse) or cumulative sound exposure at any location over the course of the entire seismic survey or any period of it. In particular, the cumulative sound exposure level can be computed over a time window of specified length preceding a given time. This yielded the acoustic covariates for various types of multivariate analyses (MVAs) aimed at detecting any significant correlation between sound exposure and changes in whale distribution or behaviour in the presence of other potential explanatory factors (Muir et al. in press a,b, Gailey et al. in press).

To assess potential effects of the airgun array noise on whale distribution and abundance, acoustic covariates capturing the magnitude of cumulative SEL from the seismic source were estimated at selected fixed locations within the distribution survey coverage (anthropogenic sounds from sources other than the airgun array were not included in the analysis). This was achieved using the same modelling approach used in the pre-season (see above). The process was 'open-loop', i.e. the predicted values were not individually adjusted using sound level information collected during the survey from deployed sensors. A degree of measurement-based calibration was provided nonetheless by the fact that the sound propagation model case used in the postsurvey estimation of pulse levels for each acquisition line was the one selected for that line during the seismic survey through the real-time matching process previously described. For each visual scan used as input in an MVA, sound covariates were calculated at a set of points (virtual receivers) offshore the observation station at which the scan was performed (Muir et al. in press $a, b$ ). Per-pulse estimates were calculated as the median of the sound level distribu- tion over depth, as opposed to the maximum over depth used in the estimation of protection zone boundaries. When investigating potential correlations between sound levels and biological responses, it is not precautionary to consider the upper bound of the former, as this would overestimate the reaction threshold. Cumulative sound exposure levels for the distribution and abundance MVAs were assessed over 5 time windows: 3 h, 8 h, 3 d, $7 \mathrm{~d}$, and since the start of seismic activity. Fig. 12 shows 2 time snapshot maps of $8 \mathrm{~h}$ cumulative SEL estimated over a grid of $1 \times 1 \mathrm{~km}$ cells used in the density MVA (Muir et al. in press a). The array ramp up phase (progressive increase in the number of active airguns over the space of several minutes to create a gradual rise in pulse levels) that preceded the acquisition of each seismic line was not included in these estimations, as its influence would have been secondary over the analysis time scale for distribution and abundance effects.

For the assessment of potential effects of noise associated with the seismic survey on whale behaviour, a richer set of acoustic covariates was considered (Gailey et al. in press) that included the cumulative SEL from seismic pulses for the entire track of observation of a whale; the average per-pulse SEL, peak SPL, kurtosis and signal to noise ratio (SNR) over fixed-length observation intervals of several minutes; and the $1 \mathrm{~s}$ SEL received at the whale's location from the seismic vessel, the near-shore behavioural observation vessel, and all nearby vessels combined. Given the greater sensitivity of behavioural responses to short-term variations in input variables compared to distribution and density responses, the acoustic covariates for the seismic source were estimated through a 'closed-loop' approach that made use of the individual pulse measurements at AUAR stations to correct the model-based estimates. This also allowed the estimation of pulse levels during the airgun array ramp-up phase, as the measured pulses at AUAR sites would reflect the progressive increase in acoustic output. The closed-loop correction was based on modelling the received pulse level (perpulse SEL) at the AUAR location closest to the whale track of interest and computing the $\mathrm{dB}$ offset between the modelled and the measured per-pulse SEL; this offset was then applied as a correction term to the modelled per-pulse SEL at the tracked whale position. A discussion of the closed-loop correction method, including statistical analysis of the residual error by using in turn the measurement sites as test estimation targets, has appeared in MVA reports for previous industrial operations in this region (Gailey 

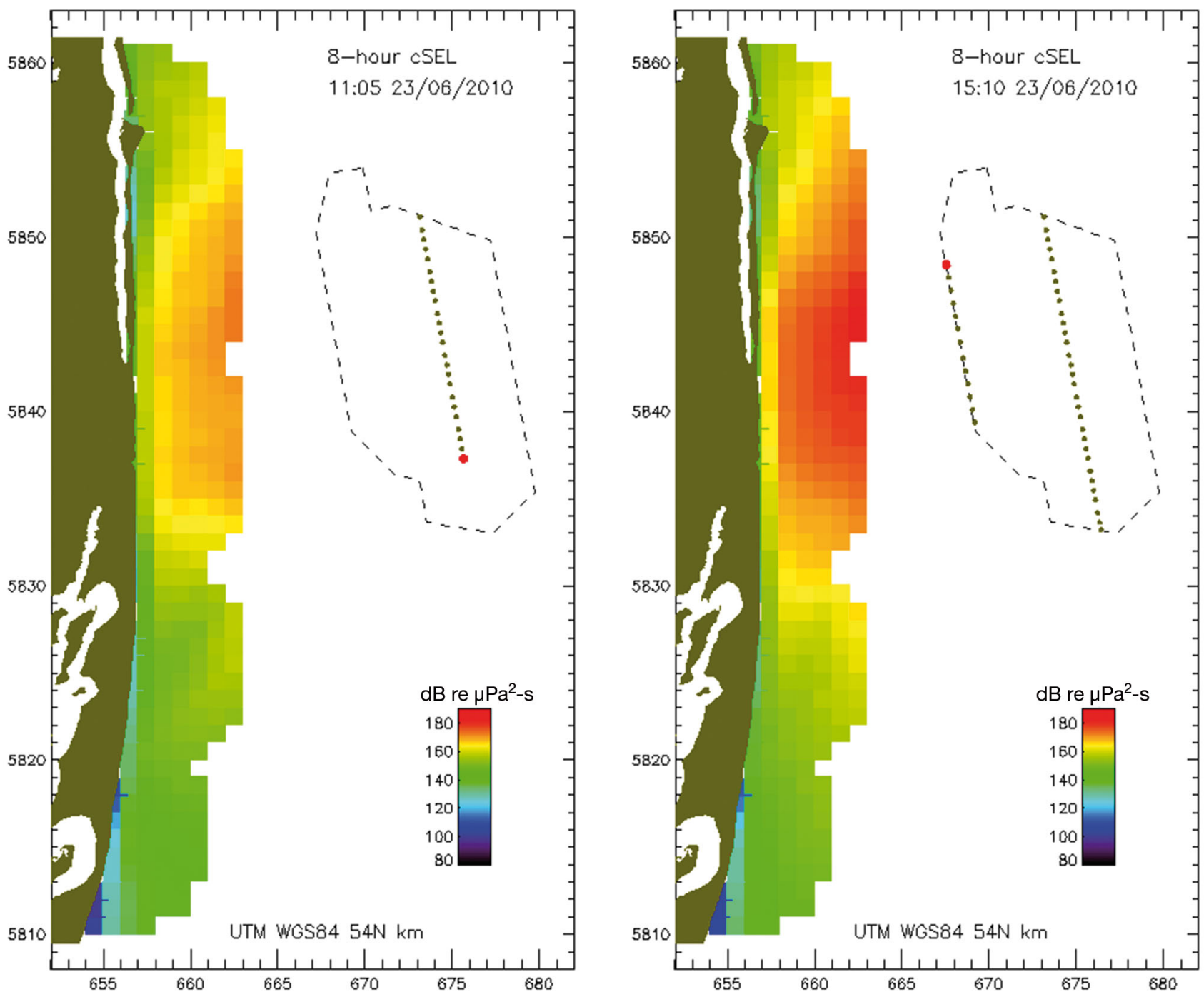

Fig. 12. Time snapshots of $8 \mathrm{~h}$ sound exposure level (SEL) accumulation from the seismic survey as estimated by modelling over a grid of $1 \times 1 \mathrm{~km}$ cells near the coast. Dashed lines are the borders of the survey region; red dot is the vessel; trailing dots represent its prior acquisition track(s) at $5 \mathrm{~min}$ intervals up to $8 \mathrm{~h}$ in the past. Dates given as dd/mm/yy. UTM: Universal Transverse Mercator; cSEL cumulative SEL

et al. 2007b, 2010). The approach for the estimation of other received pulse properties not generated by the model varied depending on the metric. The peak and rms SPL and the kurtosis could have been modelled in principle, but because they depend on the shape of the received pulse, they would have required running the propagation model at a much finer frequency resolution than 1/3-octave bands, i.e. at $1 \mathrm{~Hz}$ intervals or less, to allow synthesis of the pulse waveform - a computational requirement that could not be met. An assumption of self-similarity for pulses propagating over similar paths was made instead, and the peak and rms SPL of pulses received at the whale location were estimated by offsetting the modelled per-pulse SEL at that position by the difference between the measured peak or rms SPL metrics and the modelled pulse SEL at the nearest AUAR location. For the kurtosis and the SNR of pulses received at the whale location, the corresponding values measured at the nearest AUAR location were used. The $1 \mathrm{~s}$ SEL values from the vessels were modelled along individual propagation paths between the vessel positions, obtained either from individual GPS records or from AIS (Automatic Identification System) data broadcasts and the tracked whale locations. The exposure levels from vessels were estimated using an open-loop approach, since reference values for individual vessels could not have been derived from the sound level measurements at the AUAR sites. 


\section{CONCLUSION}

The depth of planning, extent of validation and complexity of infrastructure and analytical processing associated with the acoustic monitoring of the 2010 Astokh 4-D seismic survey are likely unmatched by any other operation of its kind executed to date, a fact justified by the small population size of the primary species of concern and made possible by the conformation of the region where the activities took place (Nowacek et al. 2013, Bröker et al. 2015). The approach relied heavily on the ability to generate verifiable footprints of acoustic propagation fronts from a seismic survey line toward shore for specific per-pulse sound exposure levels. Having the opportunity to characterize the sound field from an airgun array (albeit of different configuration) operating in the same region well ahead of the seismic survey operation provided significant information about the end to end accuracy of the source and propagation modelling at varying azimuthal angles. The sound source verification trial conducted at the start of the seismic survey validated the exclusion zone for the seismic source $(1220$ and $540 \mathrm{~m}$ for rms SPL thresholds of 180 and $190 \mathrm{~dB}$ re $1 \mu \mathrm{Pa}$, respectively) and also showed that a rapid assessment based only on broadside measurements from 3 recorders at closest approach gave essentially the same result as a more thorough analysis using a best fit function to multiple slant ranges. A precomputed library of model output cases spanning a realistic range of acoustic environment conditions enabled the immediate selection of a sound exposure footprint from measurements of received pulse levels during the first minute of each seismic line acquisition, and real-time comparison of measured to predicted levels along a set of receivers showed that the selected model case did then describe accurately the shoreward propagation of pulses along the entire line. The variability of model case selections near the beginning of the survey probably reflected a change of sound propagation conditions due to a seasonal change in hydrology. In post-survey processing, acoustic field estimation based on a combination of numerical modelling and its referencing to recorded pulse properties at the monitoring stations provided spatially resolved sound metrics - both instantaneous and cumulative - suitable to be used as covariates in statistical analyses of potential correlation of sound exposure with whale distribution or behaviour changes.
Acknowledgements. We acknowledge the tireless efforts of the Pacific Oceanological Institute acoustics team, in particular S. Borisov, D. Borovoy, V. Gritsenko, D. Kovzel, V. Likhatchev, A. Soloviev, V. Sosnin, N. Tchichov, A. Tischuk, V. Uschipovsky and P. Zakharenko, who made the acoustic monitoring program possible from instrumentation design to field analysis. Members of the Western Gray Whale Advisory Panel (especially D. Nowacek, B. Southall and A. Vedenev) under the auspices of IUCN (F. Larsen) provided valuable independent verification and consultation in matters of underwater sound science. Several scientists at JASCO Applied Sciences, most notably D. Hannay and A. MacGillivray, contributed over the years to the development of acoustic modelling and analysis methods at the core of this work. Finally, we acknowledge the financial support provided by Sakhalin Energy Investment Company.

\section{LITERATURE CITED}

Austin ME, Chapman NR (2011) The use of tessellation in three-dimensional parabolic equation modeling. J Comput Acoust 19:221-239

Borisov SV, Gritsenko AV, Dmitrieva EV, Karnauhov AA and others (2005) Acoustic studies on the north east Sakhalin Shelf, Vol 1. Equipment, methodology and data. 30 July to 7 October, 2004. Prepared for Exxon Neftegas Limited and Sakhalin Energy Investment Company, YuzhnoSakhalinsk. Available at: www.sakhalinenergy.ru/media/ user/libraryeng/environmental/whalesreports/Acoustics \%20Vol1\%20(2004)\%20Chp\%201-6.pdf (accessed 15 September 2015)

> Borisov SV, Kovzel DG, Rutenko AN, Ushchipovskii VG (2008) Stand-alone hydroacoustic station with radio channel for the acoustic measurements on the shelf. Instrum Exp Tech 51:762-767

Bröker K, Gailey G, Muir JE, Racca R (2015) Monitoring and impact mitigation during a $4 \mathrm{D}$ seismic survey near a population of gray whales off Sakhalin Island, Russia. Endang Species Res 28:187-208

Collins MD (1993) The split-step Padé solution for the parabolic equation method. J Acoust Soc Am 93:1736-1742

Erdreich J (1986) A distribution based definition of impulse noise. J Acoust Soc Am 79:990-998

Gailey G, Würsig B, McDonald TL (2007a) Abundance, behaviour, and movement patterns of western gray whales in relation to a 3-D seismic survey, Northeast Sakhalin Island, Russia. Environ Monit Assess 134:75-91

Gailey G, McDonald T, Racca R, Sychenko O, Rutenko A, Würsig B (2007b) Influences of underwater sound and nearshore vessel activity on western gray whale behavior during the installation of a concrete gravity-based structure off Sakhalin Island, summer 2005. Prepared for Exxon-Neftegas Ltd. and Sakhalin Energy Investment Company, Yuzhno-Sakhalinsk. Available at: http:// cmsdata.iucn.org/downloads/wgwap_2_inf_7__mva.pdf (accessed 15 September 2015)

Gailey G, McDonald T, Racca R, Sychenko O and others (2010) Western gray whale movement, respiration, and abundance during pipeline construction off Sakhalin Island, Russia. Prepared for Exxon-Neftegas Ltd. and Sakhalin Energy Investment Company, YuzhnoSakhalinsk. LGL Ltd, Sidney, BC

Gailey G, Sychenko O, McDonald T, Racca R, Rutenko A, Bröker K (in press) Behavioural responses of western 
gray whales to a 4-D seismic survey off northeastern Sakhalin Island, Russia. Endang Species Res, doi: 10.3354/esr00713

Hamilton EL (1976) Shear wave velocity versus depth in marine sediments: a review. Geophysics 41:985-996

Hamilton EL (1980) Geoacoustic modeling of the sea floor. J Acoust Soc Am 68:1313-1340

Hannay D, Racca R (2005). Acoustic model validation. Document 0000-S-90-04-T-7006-00-E, Revision 02. Technical report for Sakhalin Energy Investment Company by JASCO Research. Available at: www.sakhalinenergy. ru/media/acd4ec1d-483c-470a-b2b7-014ebde76eb3.pdf (accessed 15 September 2015)

IUCN (International Union for Conservation of Nature) (2008a) Report of the 4-D seismic survey task force at its 1st meeting. IUCN, Gland. Available at: http://cmsdata. iucn.org/downloads/seismic_tf__report_final_20_09_07 _with_caution_20_05_08_1.pdf (accessed 15 September 2015)

IUCN (International Union for Conservation of Nature) (2008b) Report of the 4-D seismic survey task force at its 2nd meeting. IUCN, Gland. Available at: http://cmsdata. iucn.org/downloads/seismic_task_force_report_final_ 30_06_08.pdf (accessed 15 September 2015)

IUCN (International Union for Conservation of Nature) (2009) Report of the 4-D seismic survey task force at its 4th meeting. IUCN, Gland. Available at: http://cmsdata. iucn.org/downloads/wgwap_seismic_survey_tf_report_4 .pdf (accessed 15 September 2015)

IUCN (International Union for Conservation of Nature) (2010) Report of the 4-D seismic survey task force at its 5th meeting. IUCN, Gland. Available at: http://cmsdata.iucn.org/downloads/wgwap_5th_seismic_survey_ task_force_meeting_report.pdf (accessed 15 September 2015)

Johnson SR, Richardson WJ, Yazvenko SB, Blokhin SA and others (2007) A western gray whale mitigation and monitoring program for a 3-D seismic survey, Sakhalin Island, Russia. Environ Monit Assess 134:1-19

Karnauhov AA, Kruglov MV, Rutenko AN (2005) Acoustic studies on the north east Sakhalin Shelf, Vol 2, Chap 3. Analysis, conclusions and recommendations. 30 July to 7 October, 2004. Prepared for Exxon Neftegas Limited and Sakhalin Energy Investment Company, YuzhnoSakhalinsk. Available at: www.sakhalinenergy.ru/media/ user/libraryeng/environmental/whalesreports/Acoustics \%20Vol2\%20(2004)\%20Chp\%203-4.pdf (accessed 15 September 2015)

Kovzel DG, Rutenko AN (2009) A self-contained acoustic station with a digital radiotelemetry channel for monitoring seismic acoustic signals on the shelf. Instrum Exp Tech 52:857-861

LGL (2010) Environmental impact assessment of Sakhalin Energy Investment Company's 3-D seismic programme in the Piltun-Astokh Area, Sakhalin Island, Russia. Prepared for Sakhalin Energy Investment Company Limited. Available at: www.sakhalinenergy.ru/media/ 87cb2a5c-7946-4993-a173-d5101045cfae.pdf (accessed 15 September 2015)

Editorial responsibility: Randall Reeves, Hudson, Quebec, Canada; Greg Donovan, Cambridge, UK
MacGillivray AO (2006) Acoustic modelling study of seismic airgun noise in Queen Charlotte Basin. University of Victoria, Victoria

Malme CI, Würsig B, Bird JE, Tyack P (1986) Behavioural responses of gray whales to industrial noise: feeding observations and predictive modeling. Outer Continental Shelf Environmental Assessment Program, Final report of Principal Investigators, NOAA No. PB-88249057/XAB. BBN Labs, Cambridge, MA

Malme CI, Würsig B, Bird JE, Tyack P (1988) Observations of feeding gray whale responses to controlled industrial noise exposure. In: Sackinger WM, Jefferies MO, Imm JL, Treacy SD (eds) Port and ocean engineering under Arctic conditions, Vol 2. University of Alaska, Fairbanks, AK, p 55-73

Muir JE, Ainsworth LM, Racca R, Bychkov Y and others (in press a) Gray whale densities during a seismic survey off Sakhalin Island, Russia. Endang Species Res, doi: 10.3354/esr00709

Muir JE, Ainsworth LM, Joy R, Racca R and others (in press b) Distance from shore as an indicator of disturbance of gray whales during a seismic survey off Sakhalin Island, Russia. Endang Species Res, doi:10.3354/esr00701

Muir JE, Joy R, Bychkov Y, Bröker K, Gailey G, Vladmirov V, Starodymov S, Yakovlev Y (in press c) Delineation of a coastal gray whale feeding area using opportunistic and systematic survey effort. Endang Species Res, doi:10.3354/ esr00705*

Nowacek DP, Thorne LH, Johnston DW, Tyack PL (2007) Responses of cetaceans to anthropogenic noise. Mammal Rev 37:81-115

> Nowacek DP, Bröker K, Donovan G, Gailey G and others (2013) Responsible practices for minimizing and monitoring environmental impacts of marine seismic surveys with an emphasis on marine mammals. Aquat Mamm 39: 356-377

Rutenko AN, Sosnin VA (2014) Hydrodynamic processes on the Sakhalin Shelf in the coastal Piltun area of the grey whale feeding and their correlation with atmospheric circulation. Russ Meteorol Hydrol 39:335-349

Rutenko AN, Borisov SV, Gritsenko AV, Jenkerson MR (2007) Calibrating and monitoring the western gray whale mitigation zone and estimating acoustic transmission during a 3D seismic survey, Sakhalin Island, Russia. Environ Monit Assess 134:21-44

> Rutenko AN, Borovoi DI, Gritsenko VA, Petrov PS, Ushchipovskii VG, Boekholt M (2012) Monitoring the acoustic field of seismic survey pulses in the near-coastal zone. Acoust Phys 58:326-338

> Southall BL, Bowles AE, Ellison WT, Finneran JJ and others (2007) Marine mammal noise exposure criteria: initial scientific recommendations. Aquat Mamm 33:411-521

Yazvenko SB, McDonald TL, Blokhin SA, Johnson SR and others (2007) Distribution of western gray whales during a seismic survey near Sakhalin Island, Russia. Environ Monit Assess 134:45-73

Zhang Y, Tindle C (1995) Improved equivalent fluid approximations for a low shear speed ocean bottom. J Acoust Soc Am 98:3391-3396

Submitted: July 2, 2014; Accepted: October 1, 2015 Proofs received from author(s): November 28, 2015 